\title{
Struktur dan Fungsi Sastra Lisan "Buruda” dalam Kehidupan Masyarakat Gorontalo
}

\author{
Herson Kadir, \& Ellyana Hinta \\ Universitas Negeri Gorontalo \\ E-mail: hersonung@gmail.com; ellyana.hinta@yahoo.com
}

\begin{abstract}
How to cite (in APA Style): Kadir, H., \& Hinta, E. (2020). Struktur dan fungsi sastra lisan "Buruda" dalam kehidupan masyarakat Gorontalo. Jurnal Pendidikan Bahasa dan Sastra, Vol. 20(2), 257-272. doi:https://doi.org/10.17509/bs_jpbsp.v20i2.33065
\end{abstract}

Article history: (Received: 9 Jan 2020, Revised: 15 Sept 2020, Accepted: 28 Sept 2020)

Journal homepage: http://ejournal.upi.edu./index.php/BS_JPBSP

\begin{abstract}
Abstrak.: Penelitian ini dilakukan sebagai upaya pembertahanan dan pelestarian sastra lisan Buruda sebagai bagian dari folklore daerah Gorontalo. Penelitian ini bertujuan untuk mendeskripsikan struktur dan fungsi sastra lisan buruda dalam kehidupan masyarakat Gorontalo. Penelitian ini dilakukan dengan menggunakan metode deskriptif kualitatif. Teknik pengumpulan data dilakukan dengan teknik simak melalui perekaman dan pencatatan serta teknik wawancara dilakukan terhadap informan seperti tokoh adat dan tokoh masyarakat. Data primer dalam penelitian ini ialah syair buruda yang telah diterjemahkan ke dalam bahasa Indonesia. Hasil penelitian menunjukkan bahwa struktur sastra lisan buruda berbentuk syair yang terdiri atas sepuluh bagian yaitu; (1) berisi tentang ungkapan perasaan orang yang sedang jatuh cinta; (2) peringatan bahaya hawa nafsu; (3) pujian kepada nabi Muhammad shallallahu 'alaihi wa sallam; (4) kelahiran nabi Muhammad shallallahu 'alaihi wa sallam sebagai penerang dan penunjuk jalan yang benar; (5) mukjizat yang dimilik oleh nabi Muhammad shallallahu 'alaihi wa sallam; (6) kemuliaan kitab Al-Quran berisi petunjuk keselamatan manusia di dunia dan akhirat; (7) kebenaran peristiwa isr'a dan mikraj yang dialami oleh nabi Muhammad shallallahu 'alaihi wa sallam; (8) tantangan perjuangan nabi Muhammad shallallahu 'alaihi wa sallam dalam menyebarkan risalah islam; (9) pentingnya menghindari perbuatan dosa dan maksiat karena malu kepada Allah subhanahu wa ta'ala; (10) kekuatan doa dan pentingnya bermunajat memohon ampun dan kasih sayang Allah subhanahu wa ta'ala. Selanjutnya, fungsi sastra lisan Buruda dalam kehidupan masyarakat Gorontalo berisi pesan-pesan moral berupa fungsi religius, fungsi etis, dan fungsi kultural.
\end{abstract}

Kata kunci: struktur, fungsi, sastra lisan buruda, masyarakat Gorontalo

\section{Structure and Function of Oral Literature "Buruda" in Community Life of Gorontalo}

\begin{abstract}
This research is conducted as an effort to preserve and maintain Buruda oral literature as part of the Gorontalo regional folklore. The research is aimed at describing the structure and function of buruda oral literature in the community life of Gorontalo. Moreover, this research applies a qualitative descriptive method, while the data collection technique is done by observation technique through recording and note taking, as well as interview technique that is carried out on informants such as traditional leaders and community leaders. The research finding revealed that the structures of buruda oral literature are in the form of verse that consisted of ten parts as follows: (1) contains an expression of the feelings of people who are in love; (2) warning of the danger of lust; (3) praise to the prophet Muhammad shallalahu 'alaihi wa sallam; (4) the birth of the Prophet Muhammad shallalahu 'alaihi wa sallam as the light and guide to the right way; (5) the miracle owned by the Prophet Muhammad shallalahu 'alaihi wa sallam; (6) the glory of the Qur'an contains instructions for human salvation in the world and the hereafter; (7) the truth of isra and mi'raj experienced by Muhammad shallalahu 'alaihi wa sallam; (8) the challenges of the struggle of the Prophet Muhammad shallalahu alaihi wa sallam in spreading the message of Islamic treatises; (9) the importance of avoiding sin and immorality because of ashamed to Allah subhanahu wa ta'ala; (10) the power of prayer and the importance of bermunajat (praying wholeheartedly) asking for mercy and compassion from Allah subhanahu wa ta'ala. Furthermore, the function of buruda oral literature in the community life of Gorontalo contains moral messages in the form of a religious function, ethical function, and cultural function.
\end{abstract}

Keywords: structure, function, buruda oral literature, Gorontalo community 


\section{PENDAHULUAN}

Sastra lisan menjadi salah satu pengawet pengetahuan, aktivitas sosial, kebiasaan nilai dan fungsi adat istiadat atau kebudayaan daerah suatu masyarakat. Sastra lisan tersebar di semua daerah dan menjadi aspek budaya yang sangat banyak terdapat pada masyarakat tradisional dan modern (Tuloli, 2003, p.1). Di Gorontalo berbagai sastra lisan masih terpelihara dengan baik. Salah satu sastra lisan yang masih eksis di Gorontalo adalah sastra lisan yang berkaitan dengan keagamaan, salah satunya adalah buruda. Sastra lisan ini dianggap termasuk folklore yang memiliki fungsi dan nilai yang bermanfaat bagi kehidupan masyarakat Gorontalo, sehingga sesuai dengan pandangan Danandjaja (2002, p.2) masih diwariskan secara turun temurun dan menjadi bagian kebudayaan kolektif suatu masyarakat. Sastra lisan buruda merupakan bagian dari sastra daerah yang sangat dipengaruhi oleh agama Islam. Hal itu diketahui dengan awal mulanya masyarakat Gorontalo yang berketurunan Arab, jika melaksanakan berbagai hajatan seperti pernikahan dan aqiqah (gunting rambut) selalu membacakan dan menuturkan kisahkisah yang beirisi doa, pujian, ungkapan dan nasihat-nasihat islami. Kebiasaan itu kemudian telah meregenerasi, tumbuh berkembang, dan tersebar dalam kehidupan masyarakat Gorontalo menjadi sebuah folklore. Menurut Hutomo (1991, p.7) bahwa folklore juga meliputi sastra lisan yang penyebaran bentuknya relatif tetap atau baku dalam suatu kelompok masyarakat. Sampai dengan saat ini pun, sastra lisan Gorontalo yang berkaitan dengan keagamaan, termasuk buruda telah mengkomunal dalam kehidupan masyarakat Gorontalo dan dipertahankan dengan pola yang sama.

Sastra lisan buruda termasuk sastra daerah Gorontalo yang sering disampaikan atau dibawakan pada sebuah hajatan pernikahan oleh para orang tua, tokoh adat, agama, dan tokoh masyarakat. Sastra lisan buruda menggunakan bahasa dan aksara Arab pada proses penuturan dan penceritaannya. Setelah itu, dalam proses perkembangannya lama kelamaan telah disadur dalam tulisan yang berbentuk naskah. Sastra lisan buruda memiliki struktur dan fungsi yang sangat penting untuk dikaji. Menukil pernyataan Robson (1988, p.73) bahwa pengkajian terhadap sastra lisan pengaruh islam didasari pada tiga asumsi yakni; (1) sastra islam bersumber dari nilai-nilai kebenaran yang abadi, yaitu nilai keislaman; (2) keabadian karya itu, karena difungsikan oleh pengarangnya sendiri maupun masyarakat penerimanya, maka karya yang abadi hanyalah karya yang berfungsi atau memiliki fungsi; (3) karya sastra Islam telah berkontribusi bagi perkembangan dunia sastra Indoensia terutama dalam aspek isinya. Berdasarkan hal itu tentu sastra lisan pengaruh islam termasuk buruda, perlu dikaji dan dilteliti dengan harapan dapat memberi kontribusi pengembangan dan memperkaya khazanah pengetahuan di bidang keilmuan sastra Indonesia dan daerah. Selain itu, menurut Ikram (1980, p.76) bahwa berbagai nilai seperti keindahan, kemanusiaan, moral, adat-istiadat, pendidikan, sejarah bahkan ekonomi dan politik dapat didedah dari sastra lisan, karena sastra lisan merupakan sumber yang tidak ternilai bagi setiap aspek kebudayaan. Untuk itu, kajian sastra lisan penting dan dapat dilakukan dari berbagai sudut pandang dan perspektif yang berbedabeda.

Dalam konteks penelitian ini, sastra lisan buruda dikaji dari aspek struktur dan fungsi. Hal itu dilakukan dengan alasan bahwa sastra lisan Buruda, meskipun termasuk sebagai tradisi lisan, namun kini telah diupayakan disadur dalam bentuk naskah. Penyaduran itu penting dilakukan termasuk dalam penelitian ini, karena naskah merupakan produk yang menurut Vansina (1985, p.3) bahwa produk itu dapat menjadi pesan lisan dari generasi sebelumnya. Pesan lisan tersebut tentu mengandung makna dan nilai yang bermanfaat bagi kehidupan masyarakat. Selain itu, pentingnya pengkajian fungsi sastra lisan buruda tentu diharapkan dapat memperkokoh jalinan persatuan sesuai dengan pernyataan Amir (dalam Suantoko, 2016, p.247) bahwa salah satu fungsi sastra lisan yakni berfungsi untuk membangun dan mengikat rasa persatuan kelompok. Dengan demikian, kajian fungsi sastra lisan buruda 
diharapkan pula dapat bermanfaat mempererat persatuan antarkelompok masyarakat asli Gorontalo dengan masyarakat keturunan Arab yang hidup di daerah Gorontalo.

Sastra lisan buruda sebagai budaya lokal Gorontalo sangat penting untuk dikaji, guna merebut makna penting di dalamnya. Untuk itu kajian terhadap sastra lisan buruda difokuskan pada struktur dan fungsi. Secara struktural, kajian terhadap sastra lisan buruda mengarah pada bentuk dan isi. Menilik pendapat Wellek dan Warren (dalam Firmanda, 2018, p.2) bahwa struktur dapat dimasukkan ke dalam isi dan bentuk, sejauh keduanya dimaksudkan untuk mencapai tujuan estetik. Melalui kajian struktur, perlu ditekankan bahwa selain memperoleh sesuatu yang indah, tentu dapat diperoleh pula pesan atau amanat yang bermanfaat dalam sastra termasuk pada sastra lisan buruda. Pemerolehan pesan yang bermanfaat dan bernilai di dalam sastra lisan buruda, tentu berkaitan erat dengan fungsinya dalam kehidupan masyarakat Gorontalo hingga saat ini. Hal itu sesuai dengan pandangan Ratna (2007, p.276) bahwa sastra lama meskipun dari masa lampau, tetapi relevansinya tetap ditujukan kepada masyarakat sekarang. Secara fungsional pada dasarnya sastra lisan buruda tentu memiliki pula kegunaan. Selaras dengan penegasan Astika (dalam Hestiyana, 2017, p.170) bahwa salah satu ciri sastra lisan yaitu memiliki kegunaan atau fungsi tertentu dalam masyarakat. Kegunaan atau fungsi sastra lisan tentu dapat diketahui melalui upaya ilmiah seperti kajian dan penelitian yang dilakukan.

Sehubungan dengan hal itu, maka kajian terhadap struktur dan fungsi sastra lisan buruda sangat laik dilakukan sebagai upaya untuk mempertahankan dan melestarikan sastra lokal Gorontalo. Hal itu penting, karena saat ini animo masyarakat Gorontalo mulai berkurang terhadap sastra lisan buruda. Masyarakat khususnya generasi muda saat ini mulai kurang mengenal sastra lisan buruda. Padahal di dalam sastra lisan buruda ditenggarai mengandung makna dan pesan-pesan islami yang dapat membentuk karakter dan memperbaiki akhlak masyarakat terutama para generasi muda. Berdasarkan hal itu, maka penelitian ini diangkat dengan tujuan mendeskripsikan struktur dan fungsi sastra lisan buruda dalam kehidupan masyarakat Gorontalo.

\section{METODE}

Penelitian ini merupakan jenis penelitian kualitatif dengan menggunakan metode dekriptif. Secara umum tahapan peneltian ini dilakukan dalam tiga tahapan. Menurut Endraswara (2008, p.154) ada tiga tahapan penelitian sastra lisan yaitu; (a) pengumpulan data, yaitu melaui rekaman; penggolongan atau klasifikasi, pemiliahan data; (c) analisis, serta perlu melakukan transkripsi rekaman jika sastra lisan bersifat orisinal. Data primer dalam penelitian ini adalah syair-syair buruda yang sudah disadur dalam bentuk naskah dan diperoleh dari beberapa informan yang berada di wilayah Gorontalo. Pengumpulan data dilakukan dengan dua cara yakni; (1) teknik simak dengan teknik dasar sadap atau perekaman dan pencatatan; (2) wawancara dilakukan dengan teknik dasar pancing (Mahsun, 2005: 90-94). Teknik simak dilakukan untuk merekam informan sebagai penutur yang melantunkan syair-syair buruda. Hasil rekaman itu disadur dan diterjemahkan, disalin serta dilakukan pencatatan ke dalam bahasa Indonesia agar dapat dipahami. Teknik wawancara dilakukan kepada informan sebagai penutur sastra lisan buruda untuk mengetahui arti syair-syair buruda, karena syair tersebut dilantunkan dalam bahasa Arab. Selain itu, melalui teknik wawancara tersebut digali informasi tentang makna dan fungsi sastra lisan buruda.

Setelah data terkumpul, dilakukan penganalisisian data dengan cara menyimak transkripsi rekaman. Setelah itu membaca dan memahami hasil terjemahan syair-syair buruda yang yang telah ditulis sambil pula mencatat dan mengkalisifikasi arti sekaligus memaknai isi syair buruda. Selanjutnya data dianalisis secara struktural. Analisis struktur dilakukan untuk mendeskripsikan bentuk dan isi serta memaparkan secara cermat 
keterkaitan unsur atau bagian secara menyeluruh (Teeuw, 1984, p.135-136) dari struktur sastra lisan buruda tersebut. Analisis data dilanjutkan dengan mendeskripsikan dan menginterpretasikan pesan serta fungsi sastra lisan buruda.

\section{HASIL DAN PEMBAHASAN}

Fokus dan tujuan penelitian ini mendeskripsikan struktur dan fungsi sastra lisan buruda. Paparan hasil penelitian diawali dengan pembahasan struktur sastra lisan buruda seperti berikut ini.

\section{Struktur Sastra Lisan Buruda}

Sastra lisan buruda pada dasarnya berbentuk syair-syair yang menggunakan bahasa puitis. Terdapat permainan rima yang sebahagian besar mengandung persamaan bunyi serta di dalamnya terdapat pemakaian repetisi diksi dan kalimat guna menekankan sebuah maksud. Syair-syair sastra lisan buruda terdiri atas sepuluh bagian. Setiap bagian memiliki isi dan pesan yang bermakna. Keseluruhan bagian memiliki keterkaitan satu sama lain. Syair-syairnya dilantunkan menggunakan aksara Arab, sehingga transkripsinya juga ditulis dalam bahasa Arab. Setelah itu diterjemahkan ke dalam bahasa Indonesia. Berikut ini adalah struktur sastra lisan buruda disajikan sesuai bagian-bagian yang isinya telah dimaknai dan diterjemahkan ke dalam bahasa Indonesia.

\section{Bagian Pertama: Pengaduan Cinta الفصل الأول :في الغزل وشكوى الغرام}

Dengan nama Allah Yang Maha Pengasib lagi Maha Penyayang

Apakah Karena Ingat Tetangga Di Negeri Dri Salam Sana

Engkau deraikan Air Mata Bercampur Darah Duka Atankah Karena Hembusan Angin Terarah Lurus Dari Jalan

Kadhimah

Dan Kilatan Cahaya Gulita Malam Dari Kedalaman Jurang Idham

Kenapa Kedua Matamu Tetap Menetaskan Air Mata?

Padahal Engkau Telah Berusaha Membendungnya Dan Kenapa Hatimu Senantiasa Gundab Gulana Padahal Engkau

Telab Mengbiburmya

Apakah Orang Yang Dimabuk Cinta Menyangka Babwa Api Cinta Dapat Ditutupi Nyalanya?

Di Antara Tetesan Airmata Dan Hati Yang Terbakar Membara

Andaikan Tak. Ada Cinta Yang Menggores Kalbu

Tak Mungkin Engkau Mencucurkan Air Matamu

Meratapi Puing-Puing Kenangan Masa Lalu

Berjaga Mengenang Pohon Ban Dan Gunung Yang Kau Rindu

Bagaimana Kau dapat Mengingkari Cinta Sedangkan Saksi Adil Telab Menyaksikannya

Berupa Deraian Air Mata Dan Jatub Sakit Amat Sengsara

Duka Nestapa Telab Membentuk. Dua Garisnya Isak Tangis Dan Sakit Lemab Tak Berdaya

Bagai Mawar Kuning Dan Merah Yang Melekat Pada Pipi Dua

Memang Benar Bayangan Orang Yang Kucinta Selalu Hadir Membangunkan Tidurku

Untuk. Terjaga Dan Memang Cinta Sebagai Penghalang Bagi Si empunya

Antara Dirinya Dan Kelezatan Cinta Yang Berakbir Derita

Wabai Pencaci Derita Cinta Udrrabku Kata Maaf Kusampaikan Padamu

Aku Yakin Andai Kau Rasakan Derita Cinta Ini Tak Mungkin Engkau Mencaci Maki Keadaanku Telab Sampai Padamu Tiada Lagi Rabasiaku Yang Tersimpan Darimu

Dari Orang Yang Suka Mengadu Domba Dan Derita Cintaku Tiada Kunjung Sima

Engkau Begitu Ikblas Memberi Nasehat Diriku Tetapi Aku Tak Mampu Mendengarkan Saran Itu Karena Sesunggubnya Orang Yang Dimabuk Cinta Tuli Dan Tak Menggubris Cacian Pencela Sungguh Aku Curiga Pada Uban Pemberi Saran Curiga

Pada Saran Yang Disampaikan Padabal Uban Di Kepala

Dalam Memberi Saran Jaub Dari Hal-Hal Yang Mencurigakan

Isi syair pada bagian pertama di atas, mengandung ungkapan-ungkapan perasaan seseorang yang sedang jatuh cinta. Selain itu, melalui syair di atas juga mengandung 
ungkapan kerinduan seseorang kepada orang yang disayangi atau dicintainya. Repetisi katakata /cinta/ dan frasa /yang dimabuk cinta/ muncul beberapa kali dalam syair guna memperkuat makna dan isi syair pada bagian pertama tentang pengaduan cinta.

\section{Bagian Kedua: Peringatan tentang bahaya hawa nafsu}

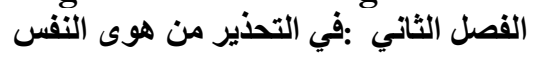

Sunggub Nafsu Marabku Pada Nasehat Tak Terima Karena Berangkat Dari Ketidaktabuannya Adanya Peringatan Berupa Uban Di Kepala Dan Ketidakberdayaan Tubuh Akibat Umur Senja Nafsu Amarabku Tak Mau Bersiap-Siap Diri Dengan Mengerjakan Amal Baik Yang Bernilai Untuk. Menyambut Kedatangan Tamu Yang Pasti Tamu Yang Singgah Di Kepala Nan Tiada Malu Lagi

Jikalau Aku Tabu Bahwa Diriku Tak Dapat Menghormat Tamu

Maka Lebih Baik. Kusembunyikan Diriku Dengan Cara Menyemir Uban Dikepalaku

Siapakah Gerangan? Sanggup Mengendalikan Nafsuku Dari Kesesatan

Sebagaimana Kuda Liar Yang Terkendalikan Dengan Tali Kekangan

Jangan Kau Berbarap Waktu Sesaat Dapat Mematabkan Nafsu Dengan Maksiat

Karena Makanan Justeru Bisa Perkuat Bagi Si Rakus Makanan Lezat

Nafsu Itu Bagai Bayi Bila Kau Biarkan Akan Tetap Menyusu Tiada Henti

Namun Bila Kau Sapib Itu Bayi Maka Ia Akan Berbenti Sendiri

Maka Palingkanlah Nafsumu Dari Kesenangan Takutlah Jangan Sampai Ia Miliki Kekuasaan

Sesunggubnya Nafsu Jikalau Berkuasa Maka Akan Membunubmu Dan Membuatmu Cela

Jagalah Hawa Nafsu Ia Bagai Ternak Dalan Kebaikan

Jika Ia Merasa Nyaman Dalam Kebaikan Itu Maka Tetap Jaga Dan Jangan Biarkan

Betapa Banyak. Kelezatan Justeru Bagi Seseorang Membawa Kematian

Karena Tiadanya Pengertian Babwa Racun Tersimpan Dalam Makanan

Waspadalah Diri Terbadap Tipu Dayanya Lapar Dan Kenyang

Sebab Sering Terjadi Rasa Lapar Lebih Daripada Kenyang

Cucurkanlah Airmata Dari Kelopak. Mata Yang Penuh Noda Dosa

Tetap Dan Pelihara Rasa Sesal Dan Kecewa

Lawanlah Hawa Nafsu Dan Setan Durjana Durbakalah Pada Keduanya

Jika Mereka Tulus Menasebati Maka Engkan Harus Mencurigai

Janganlah Engkau Taat Kepada Mereka Berdua Baik Selaku Musub Atau Selaku Hakim

Sebab Engkau Sudab Tabu Dengan Nyata Bagaimana Tipu Dayanya Musub Dan Hakim

Kumohon Ampun Kepada Allah Atas Ucapan Yang Tanpa Amaliah

Sungguh Hal Itu Kusamakan Dengan Orang Mandul Tak Berketurunan

Engkau Ku Perintah Lakukan Kebaikan Namun Aku Sendiri Tak Mengerjakan

Maka Tiada Berguna Ucapanku Agar Kau Berlaku Lurus Sedangkan Diriku Sendiri Tak Lurus

Sebelum Mati Aku Tak Cari Perbekalan Dengan Mengerjakan Ibadab Yang Disunatkan

Aku Tak. Pernah Shalat Dan Puasa Kecuali Ibadah Wajib Saja.

Syair bagian kedua berisi tentang pesan, ungkapan serta peringatan tentang bahaya dari hawa nafsu. Hal itu ditandai dengan pengulanagan kata-kata / hawa nafsu/ dan /nafsumu-nafsuku/ dalam syair tersebut.
Selain itu, melalui syair di atas dijelaskan pula tentang bahaya hawa nafsu yang hanya dapat dicegah dengan berpuasa, rajin shalat, dan mengerjakan ibadah-ibadah sunnah lainnya.

\section{Bagian Ketiga: Pujian kepada Nabi Muhammad Shallallahu 'alaihi Wasallam الفصل الثالث :في مدح سيد المرسلين صلى الله عليه وسلم}

Kutinggalkan Sunnah Nabi Nabi Yang Beribadah Saat Gulita Laili

Hingga Telapak Kaki Sakit Membengkak Merintib

Nabi Yang Karena Lapar Mengikatkean Batu Pada Pusar 
Dan Juga Dengan Batu Mengganjal Perut Nan Halus Itu

Gunung Emas Yang Mendulang Tinggi Kendati Menawarkan Diri

Namun Ia Tolak Itu Permintaan Dengan Bangga Perasaan

Sunggub Menambah Kezubudan Butub Harta Namun Tolak Permintaan

Sesunggubnya Butuh Harta Keduniaan Tidaklah Merusak Nilai Kesucian

Bagaimana Mungkin Nabi Nan Mulia Tertarik Kepada Kemilau Dunia

Padahal Tanpa Wujudnya Baginda Dunia Takkean Pernah Ada

Mubammad pemimpin dunia dan akbirat, jin dan manusia, serta pemimpin dua bangsa: Arab dan Ajam Nabi Kita Adalah Penganjur Kebaikan Dan Pencegah Kemungkaran

Tak Seorangpun Lebih Baik Daripada Ia Dalam Berkata Tidak Dan Ya

Beliaulah Kasib Kinasih Allah Ta'ala Yang Dibarap Syafa'atnya

Dari Tiap Ketakutan Dan Babaya Yang Datang Menakutkan

Beliau Mengajak Kepada Agama Allah Ta'ala Orang Yang Berpegang Tegub Padanya

Berarti Ia Berpegang Pada Tali Tali Yang Takkan Putus Secara Pasti

Beliau Mengungguli Para Nabi Baik. Bentuk Tubuh Ataupun Budi

Mereka Takkan Menyamai Dalam Ilmu Atau Kemulian Nabi

Semua Para Nabi Meminta Dari Diri Rasul Allah Ta'ala

Seciduk Lautan Ilmunya Dan Setetes Hujan Kesantunannya

Berdirilab Mereka Anbiya Disisi Nabi Pada Puncak. Mereka

Mengharap Setitik Ilmu Dan Seharakat Hikmah Beliau

Dialah Nabi Yang Sempurna Baik. Batin Atau Labirnya

Terpilib Sebagai Kekasib Allab Ta'ala Pencipta Manusia

Dia Sang Nabi Tersuci Dari Persamaan Dalam Segala Kebaikan

Inti Kebaikan Pada Diri Nabi Tak. Mungkin Terbagi

Tinggalkan Tuduban Orang Nasrani Tuduhan Yang Dilontarkan Kepada Nabi Mereka

Tetapkanlah Untaian Puji Kepada Nabi Pujian Apapun Yang Engkau Suka

Nisbabkan Kepada Zat Nabi Segala Kemulian Yang Engkau Kehendaki

Nisbabkan Kepada Martabat Nabi Segala Keagungan Yang Engkau Kehendaki

Karena Keutamaan Rasul Allab Ta'ala Tiada Tepi Batasnya

Sehingga Mengurai Mudah Terasa Bagi Lisan Yang Berkata

Bila Keagungan Mukjizat Baginda Sama Dengan Ketinggian Derajatnya

Maka Sebutan Namanya Dapat Hidupkan Orang Yang Hancur Tulangnya

Nabi Tidaklah Menguji Kita Dengan Apa Yang Tak Terjangkau Akal Manusia

Karena Sangat Cintanya Kita Beroleh Cahaya Hingga Tiada Ragu Bimbang

Pada Apa Yang Ia BawaSelurub Makbluk. Tiada Akan Mampu Memahami Hakikat Nabi

Takkan Melihat Dari Dekat Atau Jauh Kecuali Lemah Tak Berdaya Berdiam Diri

Ia Bagaikan Matahari Dari Jauh Tampak. Kecil Pada Kedua Mata

Padahal Mata Tiada Kan Mampu Bila Berdekatan Dengannya

Bagaimana Kaum Ketabui Hakikat Nabi Semasa Dalam Dunia Ini

Sedangkan Mereka Lega Jumpa Nabi Walau Dalam Sekilas Mimpi

Puncak Pengetabuan Tentang Nabi Babwa Ia Adalab Manusia

Dan Babwasanya Nabi Sebaik. Baik. Makbluk Semuanya

Semua Mukjizat Yang Datang Tiba Dibawa Para Rasul Mulia

Hanyalah Pancaran Nur Rasul Allah Ta'ala Nur Yang Melekat Kepada Mereka

Dalam Keutamaan Nabi Bak Sang Surya Sedang Para Nabi Bintang Gemintangnya

Bintang Pantulkan Sinar Surya Kepada Manusia Dalam Suasana Gelap Gulita

Alangkah Mulia Pribadi Nabi Terbias Budi Pekerti

Keindahan Yang Dimiliki Paras Wajabnya Tampak Berseri

Kehalusannya Bagai Bunga Kemuliaannya Bagai Purnama

Kedermawanannya Bagai Samudera Cita-Citanya Bagai Perjalanan Masa

Seakan-Akan Beliau Nabi Orang Yang Menyendiri

Di Antara Para Pasukan Dan Pelayan Kala Kau Jumpa Karena Dampak Keagungannya

Seakan mutiara, nan tersimpan dalam kerang, keluar dari dua sumber, ucapan dan senyumnya. Tiada Keharuman Melebihi

Tanah Buana Tanah Yang Mengubur Jasadnya

Betapa Bahagia Orang Yang Mencium Dan Mengecupnya 
Syair bagian ketiga di atas berisi dan bermakna sebagai pujian kepada nabi Muhamad shallallahu 'alaihi wa salllam yang dijadikan sebagai suri tauladan umat manusia dan kaum muslimin. Hal itu ditandai dengan pemakaian beberapa larik yang menggambarkan sanjungan di antaranya; /nabi segala keagungan/, / nabi sebaik baik makhluk semuanya/, /nabi bak sang surya/, /kemuliannnya bagai purnama/. Sanjunga sperti itu dilantunkan dikarenakan nabi Muhammad telah membawa umat manusia yang ketika itu masih pada masa Jahiliyah (masa kebodohan), menuju alam yang penuh dengan segala ilmu pengetahuan. Nabi Muhammad shallallahu 'alaihi wa salllam menjadi penanda kecerdasan bagi umatnya dan sebagai seberkas cahaya yang muncul ketika keadaan gelap gulita.

\section{Bagian Keempat: Kelahiran Nabi Muhammad Shallallahu 'alaihi Wasallam الفصل الرابع :في مولده عليه الصلاة والسلام}

Kelahiran Sang Nabi Menampakkan Kesucian Diri Alangkah Indah Permulaannya Juga Indah Penghabisannya

Hari Kelahiran Baginda Saat Ada Firasat Bangsa Persia

Bahwa Ada Peringatan Kepada Mereka Datangnya Bencana Dan Siksa

Saat Menjelang Malam Tiba Istana Kisra Hancur Terbelah

Sebagaimana Kumpulan Sahabat Kisra Tiada Menyatu Terpecah Belah

Api Sesembahan Padam Karena Duka Yang Mencekam

Sungai Eufrat Tak Mengalir Muram Karena Susah Yang Amat Dalam

Penduduk Negeri Sawah Resah Duka Saat Danaunya Kering Keronta

Pengambil Air Kembali Dengan Tangan Hampa Kecewa Ketika Terjerat Rasa Dahaga

Seakan Akan Pada Api Nan Membara Terdapat Cairan Air Karena Duka

Dan Pada Air Nan Sejuk Segar Api Yang Membakar

Para Jin Menjerit Suara Cahaya Membumbung Ke Angkasa

Kebenaran Tampak. Nyata Dari Makna Maupun Kata

Mereka Buta Dan Tuli Tak Dengar Hingga Kabar Gembira Tiada Didengar

Begitu Juga Kilatan Peringatan Sama Sekali Tak Terbiraukan

Para Dukun Mereka Telah Kabarkan Berita

Babwa Agama Mereka Bengkok Tak Bertahan Lama

Setelah Mereka Menyaksikan Bintang - Bintang Di Ufuk Berjatuhan

Bersamaan Di Bumi Ada Kejadian Berbala-Berbala Runtuh Bergelimpangan

Hingga Lenyap Syetan Berlari Dari Pintu Langit Jalan Wabyu Ilabi

Mereka Lari Mengikuti Syetan Nan Berlari Tak Henti

Seakan - Akan Syetan Yang Berlari Duka Laksana Prajurit Raja Abrabah

Atau Laksana Kumpulan Tentara Terlempari Kerikil Tangan Rasulullah

Batu Yang Nabi Lemparkan Setelah Bertasbih Dalam Genggaman

Bak Terlemparnya Nabi Yunus Dari Telanan Perut Ikan Paus

Syair bagian keempat di atas berisi tentang kisah kelahiran nabi Muhammad shallallahu 'alaihi wa sallam, yang dengan kelahiran beliau telah terjadi beberapa peristiwa besar. Saat kelahiran nabi telah memberikan firasat kepada bangsa persia tentang peringatan terhadapa mereka akan datangnya bencana dan siksa. Hal itu ditandai melalui beberapa larik seperti; /istana kisra hancur terbelah/, /api sesembahan padam/, /sungai eufrat tak mengalir/, /para jin menjerit/. Melalui syair ini dapat diketahui bahwa pada kenyataanya, kelahiran nabi Muhamad shallallahu 'alaihi wa salllam adalah salah satu penerang yang menjadi penanda hancurnya segala bentuk kebatilan dan kesyirikan. Kelahiran nabi menjadi petunjuk 
arah pada jalan kebenaran dari segala askpek kehidupan.

\section{Bagian Kelima: Mukjizat Nabi Muhammad Shallallahu 'alaihi wa sallam معزاته صلى الله عليه وسلم صل الخامس :في}

Pepohonan Datang Memenubi Panggilannya Dengan Sikap Tunduk Sopan

Berjalan Menghadap Kepadanya Dengan Batang Tanpa Telapak Terciptakan

Seakan - Akan Itu Pepohonan Tuliskan Sebuah Lukisan

Lukisan Indah Menawan Ditulis Dahan Ditengah Jalan

Sebagaimana Gumpalan Awan Ke Mana Saja Nabi Pergi

Ia Sebagai Payung Perlindungan Dari Sengatan Panas Mentari Siang Hari

Aku Bersumpah Demi Penguasa Rembulan Nan Pecab

Sesunggubnya Hati Nabi Nan Terbelah Bak Bulan Yang Dibelah

Dalam Gua Tsur Nabi Bersembunyi Abu Bakar Sababat Yang Menyertai

Semua Mata Kafir Jadi Buta Tak Dapat Melibat Orang Dua

Nabi Dan Abu Bakar Terpecaya Keduanya Berada Dalam Gua

Mereka Kafir Berkata Tak Seorang Pun Dalam Gua

Mereka Menduga Merpati Takkan Berputar Sekitar Gua

Laba Laba Takkan Bersarang Di Mulut Gua Jika Sebaik - Baik. Makbluk. Di Dalamnya

Perlindungan Allah Rabbi Tiada Butub Lagi

Pada Baju Berlapis Besi Dan Benteng Benteng Nan Tinggi

Tak Pernah Roda Masa Menganiaya Lalu Ku Mohon Bantuan Baginda

Kecuali Ku Dapatkan Pertolongannya Tanpa Rasa Hina Dina

Tak Pernab Kupinta Dari Nabi Kekayaan Dunia Dan Akbirat Nanti

Kecuali Ku Dapatkan Pemberian Dan Sebaik - Baik Orang Yang Dapat Penyerahan

Janganlah Kau Ingkari Wabyu Yang Didapat Dalam Mimpi

Karena Beliau Memiliki Hati Tak Pernab Tidur Walau Dua Mata Tertutup Rapi

Demikian Itu Terjadi Tatkala Beliau Diangkat Menjadi Nabi

Maka Tak Perlu Diingkari Keadaan Nabi Yang Bermimpi

Allab Maha Suci Wabyu Tiada Dapat Dicari

Take Ada Seorang Nabi Dalam Berita Gbaibnya Dicurigai

Betapa Banyak. Orang Sakit Sembub Ketika Telapak Tangannya Menyentuh

Dan Menyelamatkean Orang Yang Butub Dari Tali Gila Yang Terus Kambuh

Doa Nabi Dapat Hidupkan Tahun Kering Nan Tiada Hujan

Hingga Bak Titik Putib Di Muka Dalam Lipatan Hitamnya Masa

Dengan Awan Yang Hujannya Deras Hingga Kau Duga Jurang Nan Luas

Air Mengalir Dari Samudera Atau Mengalir Dari Lembah Yang Menganga

Pada syair bagian kelima ini, bermakna ataupun menceritakan tentang mu'zijat-mu'zijat dan kelebihan yang Allah subhanahu wa ta'ala berikan kepada Nabi muhammad shallallahu 'alaihi wa sallam. Ternyata banyak mu'zijat dan kelebihan beliau, salah satunya dalam syair di atas semua tumbuhan tunduk sopan terhadap beliau. Seperti ditampakkan melalui larik; /pepohonan dating memenuhi panggilannya dengan tunduk sopan/ dan saat beliau berjalan atau bepergian selalu dipayungi oleh gumpalan awan seperti terlihat pada larik; / Sebagaimana Gumpalan Awan Ke Mana Saja Nabi Pergi/ dan /Ia Sebagai Payung Perlindungan Dari Sengatan Panas Mentari Siang Hari/. Nabi shallallahu 'alaihi wa sallam memiliki banyak mukjizt terutama dalam hal kemampuan berdoa yang segera dikabulkan oleh subhanahu wa ta'ala seperti segera turunnya hujan di masa kekeringan dan sembuhnya orang-orang yang sakit karena sentuhan tangan beliau. 


\title{
Bagian Keenam: Kemuliaan Al-Quran Al-Karim dan Pengagungannya الفصل السادس :في شـرف الـقرآن ومدحـه
}

\author{
Biarkan Aku Mengurai Mukjizat Yang Tampak Pada Nabi \\ Tampak Bagai Api Jamuan Malam Hari Di Atas Gunung Menjulang Tinggi \\ Mutiara Bertambah Indah Anggun Bila Ia Rapi Tersusun \\ Nilainya Tak Berkurang Sedikitpun Walau Tak Tersusun \\ Maka Apakah Yang Menyampaikan Angan-Angan Orang Yang Memuji \\ Pada Akblak Mulia Nabi Pilihan Dan Sifat Sifat Terpatri Pada Nabi \\ Ayat-Ayat Al-Quran Adalah Dari Tuhan Nan Rahman \\ Baru Turunnya, Terdabulu Maknanya Dan Sifat DZat Yang Bersifat Qidam Punya \\ Ayat-Ayat Al-Quran Tak Bersamaan Denga Zaman \\ Dan Ia Pada Kita Telah Kabarkan Tentang Akbirat, Kaum 'Ad Dan Kota Iram \\ Ayat Ayat Ilahi Disisi Kita Kekal Abadi \\ Mengungguli Mukjizat Para Nabi Mukjizat Yang Datang Tiada Lestari \\ Sungguh Kokoh Itu Al-Quran Tak Tinggalkean Keserupaan \\ Bagi Yang Punya Perselisihan Dan Tak Usah Cari Hakim Kebenaran \\ Sama Sekali Al-Quran Takkan Ditentang Kecuali Akan Kembali Dari Medan Perang \\ Musub Yang Sangat Hebat Dan Pasrah Dalam Keadaan Tunduk Dan Pasrah \\ Keindahan Sastranya Menakluk.kan Penentangnya \\ Bagai Pencemburu Membela Keluarganya Dari Tangan Jabil Yang Menjamabnya \\ Bagi Al-Quran Berlimpah Banyak Makna Bertambah Tambah Bak Ombak Samudera \\ Keindahan Dan Nilainya Melebibi Mutira Samudera \\ Keajaiban Ayat Ayat Al-Quran Tak Bisa Dibatasi Hitungan \\ Maknanya Nan Banyak Bertebaran Sama Sekali Tak Membosankan \\ Sejuklah Mata Pembacanya Lalu Kukatakan Padanya \\ Sungguh Anda Telah Beroleh Bahagia Berpeganglah Selalu Pada Tali Allab Ta ala \\ Jika Karena Takut Kau Membacanya Dari Panas Neraka Ladha \\ Maka Kau Padamkan Panasnya Karena Kesejukan Airnya \\ Al-Quran Laksana Telaga Dapat Putibkan Wajah \\ Wajah Para Pendosa Wajah Nan Hitam Arang Tak Cerah \\ Al-Quran Tegak Bak Lurusnya Jalan Laksana Keadilan Timbangan \\ Keadilan Selain Al-Quran Di Kalangan Manusia Tiada Yang Langgeng Bertahan Lama \\ Jangan Heran Pada Pendengki Yang Berusaha Mengingkari \\ Pura Pura Bodoh Diri Padahal Ia Cerdas Dan Memahami \\ Terkadang Mata Sakit Mengingkeari Pada Sinar Matahari \\ Segar Air Tekadang Mulut Pungkiri Karena Sakit Yang Menyelimuti
}

Pada syair keenam ini, berisi tentang kemuliaan Al Quran dan pengagungannya. serta pujian-pujian terhadap kitab suci tersebut. Hal itu tampak jelas pada beberapa pilihan kata/Al Quran/ berulang-ulang dan larik seperti; /Ayat-Ayat Al-Quran Adalah Dari Tuhan Nan Rahman/ Bagi Al-Quran Berlimpah Banyak Makna/Keindahan Dan Nilainya Melebihi Mutiara Samudera/,/Keajaiban Ayat Ayat AlQuran Tak Bisa Dibatasi Hitungan/,
/Maknanya Nan Banyak Bertebaran Sama Sekali Tak Membosankan/. Kemuliaan Al Quran menjadikan setiap hamba beriman wajib membaca, mentadaburi, dan mengamalkan isinya dalam kehidupan seharihari. Selain itu dalam syair ini disampaikan makna tentang kemuliaan Al-Quran yang diturunkan oleh Allah subhanahu wa ta'ala guna menjadi petunjuk kebenaran bagi kehidupan manusia agar selamat dunia dan akhirat. 


\section{Bagian Ketujuh: Isra' Mi'raj Nabi Muhammad Shallallahu 'alaihi wa sallam الفصل السابع :في إسرائه ومعراجه صلى الله عليه وسلم}

Wahai Sebaik- Baiknya Manusia Para Pencari Kebaikan Menuju Kediamannya

Dengan Berjalan Kaki Atau Unta Yang Cepat Berlari

Wahai Nabi Nan Jadi Pertanda Besar Bagi Pencari I tibar

Duhai Nabi Nan Sebagai Nikmat Agung Bagi Orang Yang Ingin Beruntung

Dikala Malam Engkau Berjalan Dari Masjidil Haram Ke Masjidil Aqsha

Bagai Purnama Yang Berjalan Menembus Malam Gulita

Dan Engkau Terus Meninggi Hingga Suatu Tempat Engkau Gapai

Yaitu Tempat Sekira - Kira Busur Dua Tak Bisa Dicapai Dan Diasa

Para Nabi Dan Utusan Mempersilabkan Anda Di Depan

Laksana Penghormatan Pelayan Kepada Sang Majikan

Engkau Tembus Langit Tujub Petala Bersama Para Rasul Dan Anbiya'

Dalam Kumpulan Malaikat Allah Ta ala Engkaulah Menjadi Pemimpinnya

Hingga Tak. Satu Puncak. Kau Sisai Bagi Orang Yang Ingin Mendabului

Tempat Dekat Dan Tempat Tinggi Bagi Pencari Derajat Tinggi

Dibandingkan Dengan Derajatmu Derajat Jadi Rendab Semua

Karena Dengan Khusus Dipanggil Namamu Bak. Mufrad 'Alam

Dalam Kekhususannya

Agar Kau Peroleh Hubungan Sempurna Tertutup Dari Pandangan Mata

Dan Rabasia Nan Tiada Terbuka Tersimpan Dari Makbluk. Tercipta

Kau Kumpulkan Semua Kebanggaan Keutamaan Nan Tak Terbagi

Kau Lewati Setiap Derajat Ketinggian Derajat Nan Tak Terdesaki

Sungguh Agung Nilainya Derajat Yang Kau Dapati

Sungguh Jarang Lagi Langka Dapatkan Nikmat Yang Engkau Diberi

Kabar Gembira Wahai Golongan Umat Islam

Bagi Kita Tiang Kokoh Jaya Takkan Roboh Padam

Tatkeala Allab Panggil Nabi Pengajak Kita Karena Ketaatannya Kepada Allab

Dengan Panggilan Rasul Termulia Maka Jadilah Kita Umat Yang Paling Mulia

Isi syair bagian ketujuh di atas mengambarkan tentang adanya peristiwa isra mi'raj yang dialami oleh nabi Muhammad shallallahu 'alihi wa sallam. Kejadian isra mi'raj merupakan hal kabar gembira bagi semua orang muslim, karena perintah shalat diterima pada saat itu. Hal itu sangat jelas terurai melalui beberapa larik seperti; /Dikala Malam Engkau Berjalan Dari Masjidil Haram Ke Masjidil Aqsha/, /Bagai Purnama Yang Berjalan Menembus Malam Gulita/, /Engkau Tembus Langit Tujuh Petala Bersama Para Rasul Dan Anbiya',
/Dalam Kumpulan Malaikat Allah Ta`ala Engkaulah Menjadi Pemimpinnya/. Jadi, melalui syair di atas dinyatakan bahwa peristiwa isra mi'raj bukan hanya menjadi sebuah persitiwa yang hanya diperingati melalui berbagai kegiatan seremonial semata. Namun, harus diyakini dan dipahami di dalamnya terdapat perintah untuk mengerjakan shalat lima waktu yang harus diamalkan dalam kehidupan oleh semua umat muslim yang beriman kepada Allah subhanahu wa ta'ala.

\section{Bagian Kedelapan: Perjuangan Nabi Muhammad Shallallahu 'alaihi wa sallam} الفصل الثامن :في جهاد النبي صلى الله عليه وسلم

Berita Kenabian Jadiakan Hati Musub Gentar Ketakutan

Bak Lolongan Srigala Takutkan Kambing Nan Lupa

Nabi Tiada Henti Musub Dilawan Dalam Setiap Medan Pertempuran 
Hingga Daging Mereka Bertumpukan Laksana Daging Di Tempat Pemotongan

Mereka Ingin Lari Hampir Saja Mereka Berharap Diri

Anggota Badan Nan Hancur Menjaubi Terbang Bersama Burung Rakbmab Dan Rajawali

Siang Malam Berlalu Hitungannya Mereka Tak Tahu

Selagi Siang Malam Tak Berada Dalam Bulan - Bulan Nan Mulia

Islam Datang Bagai Tamu Undangan Singgab Di Halaman Sababat Nabi

Bersama Orang - Orang Jantan Yang Sangat Ingin Membunub Musub Islami

Ia Membawa Lautan Pasukan Diatas Kuda Yang Berenang Jaya

Membawa Para Pemberani Lagi Jantan Bagai Debur Ombak Samudera

Setiap Orang Yang Penubi Panggilan Allah Dan Mengharap Pabala Di Sisi Allah

Menyerang Akar Kekufuran Dengan Pedang Pembasmi Memusnabkan

Berkat Kegigihan Para Ksatria Hingga Jadilah Islam Agama

Setelah Terasing Jaub Dari Pemeluknya Terjalin Erat Hubungan Keluarga

Islam Terjamin Selamanya Dari Mereka Dengan Sebaik-Baik Aba

Dan Sebaik-Baik Suami Tercinta Mereka Takkan Jadi Yatim Dan Janda

Mereka Ksatria Bak Gunung Nan Kokob Kuat

Maka Tanyakan Lawan Tentang Hebatnya Gempuran

Apa Yang Mereka Libat Dalam Setiap Medan Peperangan?

Coba Kau Tanyakan Hunain, Badar Dan Ubud Sebagai Ajang Peristiwa

Semuanya Tempat Macam Kematian Terasa Lebih Ganas Dari Wabab Kolera

Pedang Mereka Nan Putib Berkilauan Kembali Menjadi Merab Padam

Setelah Banyak. Memenggal Leher Lawan Hitam Sehitam Rambut Nan Kelam

Dengan Kayu Khat Sebagai Tombak Senjata Mereka Tusukkan Pada Para Musub

Tombak Pena Takkan Tinggalkan Sisa Daging Terkoyak Dari Tubub

Para Tentara Nan Tajam Senjatanya Miliki Tanda Pembeda

Bak Mawar Nan Mempesona Dengan Pohon Salam Ada Tanda Pembeda

Angin Kemenangan Kirimkan Padamu Semerbak Keharuman Tentara

Hingga Bunga Di Kelopak Tersangka Olehmu Tentara Nan Gagah Perkasa

Seakan - Akan Mereka Dipunggung Kuda Laksana Pepohonan Di Bukit Tinggi

Karena Kuatnya Kemantapan Belaka Bukan Karena Kuatnya Tali

Hati Para Musub Goncang Duka Karena Takut Serangan Dabsyat Para Ksatria

Maka Tak Dapat Bedakan Antara Kumpulan Anak Domba

Dan Sekelompok Pemberani Perkasa

Barangsiapa Meraib Kemenangan Sebab Rasulullah Nabi Piliban

Bila Singa Di Rimba Menjumpainya Maka Akan Diam Tunduk Padanya

Tak. Kau Lihat Kekasib Beriman Kecuali Beroleb Kemenangan

Dan Tak Kau Libat Musuh Nabi Utusan Kecuali Mendapat Kekalaban

Nabi Tempatkan Umatnya Dalam Benteng Agamanya

Bak Singa Tempatkan Anak - Anaknya Dalam Hutan Belantara

Seringkali Kitab Suci Al-Quran Jatubkean Musub Dalam Perdebatan

Dan Telah Banyak Dalil - Dalil Pasti Kalabkan Musub - Musub Sejati

Cukup Bagimu Sebagai Mukjizat Ilmu Nabi Nan Ummi Labir Di Zaman Kebodohan

Dan Cukup Bagimu Sebagai Mukjizat Adab Nabi Nan Yatim Tanpa Guru Pendidikan

Pada isi syair bagian kedelapan di atas digambarkan tentang perjuangan nabi Muhammad shallallahu 'alihi wa sallam dalam menyebarkan agama Islam. Banyak peperangan seperti badar, hunain, dan uhud yang telah dilalui oleh beliau dan banyak para sahabat yang gugur sebagai syuhada. Hal itu tampak pada beberapa larik berikut; /Apa Yang Mereka Lihat Dalam Setiap Medan Peperangan?/, /Coba Kau Tanyakan Hunain, 
Badar Dan Uhud Sebagai Ajang Peristiwa/, /Barangsiapa Meraih Kemenangan Sebab Rasulullah Nabi Pilihan/,/Tak Kau Lihat Kekasih Beriman Kecuali Beroleh Kemenangan/, /Dan Tak Kau Lihat Musuh Nabi Utusan Kecuali Mendapat Kekalahan/, /Nabi Tempatkan Umatnya Dalam Benteng Agamanya/. Syair di atas memberikan penjelasan bahwa islam tidak suka kekerasan, selama tidak diperangi. Adapun peristiwa peperangan yang digambarkan di dalam syair tersebut bukan merupakan suatu kejahatan, namun perang itu terjadi atas kehendak Allah subhanahu wa ta'ala akibat perbuatan buruk dari orang-orang kafir qurays di zaman itu. Bahkan di beberapa peristiwa perang itu pun menjadi ajang peristiwa diberikannnya hidayah kepada orang-orang tertentu. Perjuangan beliau shallallahu 'alaihi wa sallam dalam menyampaikan ajaran islam selalu dilakukan dengan sikap lemah lembut, jujur, amanah, sederhana, tidak memaksa, dan suka mengalah. Terutama adalah selalu berlandasakan pada Al Quran sebagai wahyu, sehingga tidak dapat dibantah dengan dalil apapun. Beliau adalah nabi tanpa guru, namun beliau dididik langsung oleh Allah, Sang Maha meliputi segala pengatahuan melalui wahyu yang dibawa oleh malikat Jibril 'alaihi sallam disampaikan kepada baginda rasulullah shallallahu alaihi wa sallam. Beliau berhasil menempatkan umatnya di dalam benteng agama islam yang kokoh.

Bagian Kesembilan: Nabi shallallhu 'alaihi wa sallam sebagai penjamin dan pemberi syafaat di akherat

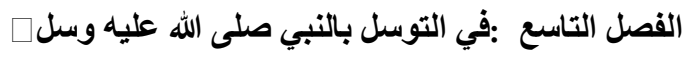

Kupuja Nabi Dengan Pujian Kumohon Adanya Pengampunan

Dosa-Dosa Hidup Yang Terlewatkan Dalam Bersyair Dan Pujian

Keduanya Mengalungi Diriku Sesuatu Yang Menakutkan Akibatnya Dengan Dua Perkara Itu

Seakan Akan Diriku Hewan Sembelihan Berupa Unta

Kuturuti Bujuk Rayu Masa Muda Dalam Bersyair Dan Memuja

Tak. Ada Yang Ku Dapatkan Kecuali Dosa Dan Penyesalan

Alangkah Ruginya Jiwa Dalam Perdagangannya

Tak Pernah Beli Agama Dengan Dunia Dan Pernah Menawarnya

Barangsiapa Menjual Akbirat Dengan Dunia Kebahagian Sesaat

Maka Nyata Baginya Kerugian Dalam Jual Beli Dan Akad Pesan

Jika Dosa Kulakukan Janjiku Pada Nabi Tidaklah Terputuskan

Dan Juga Tali Hubungan Takkan Terputuskan

Sesunggubnya Ku Punya Jaminan Namaku Muhammad Sesuai Dengan Nabi

Nabi Lebih Sempurnanya Makbluk Ciptaan Dalam Menepati Janji

Jika Di Akbirat Nabi Tak. Ulurkan Tangan Menolongku Sebagai Fadhal Keutamaan

Maka Sampaikanlah Kata "Wahai Orang Yang Tergelincir Kakinya"

Maha Suci Allab Ta ala Nabi Tak Tolak Pengharap Syafaatnya Atau Tetangga Tak Kembali Darinya Tanpa Dihormat Dan Dimulia

Sejak Kucurabkan Segala Pikiran Untuk. Memberikan Aneka Pujian

Maka Untuk Keselamatanku Nabi Kudapatkan Sebaik Baik Pemberi Jaminan

Pemberian Nabi Takkan Luputkan Setiap Tangan Yang Membutubkan

Sesenggubnya Hujan Akan Menghidupi Bunga - Bunga Di Bukit Tinggi

Aku Tidaklah Mengharapkan Dunia Yang Penub Kenikmatan

Seperti Yang Zubair Petik Dengan Tangannya Atas Raja Haram Yang Ia Pujan

Isi syair bagian kesembilan di atas bermakna, pentingnya menghindari perbuatan dosa dan maksiat karena malu kepada Allah dan Rasul-NYA. Untuk itu perlu mempelajari dan mengamlakan ilmu agama. Tidak berlebihan mengejar dunia dan lebih mengutamakan akhirat melalui amal ibadah yang sesuai dengan petunjuk Rasulullah shallallahu alihi wa sallam. Hal itu dapat dijadikan modal untuk mendapatkan jaminan dan syafaat dari rasulullah shallahu alaihi wa sallam di akhertat kelak. Pesan itu tertuang dalam beberapa larik seperti; /Jika Di Akhirat Nabi Tak Ulurkan 
Tangan Menolongku Sebagai Fadhal Keutamaan/, /Maka Sampaikanlah Kata "Wahai Orang Yang Tergelincir Kakinya"/, / Maha Suci Allah Ta`ala Nabi Tak Tolak Pengharap Syafaatnya Atau
Tetangga Tak Kembali /Maka Untuk Keselamatanku Nabi Kudapatkan Sebaik Baik Pemberi Jaminan/. Larik syair ini memperjelas isi pentingnya beribadah sesuai sunah Rasul.

\section{Bagian Kesepuluh: Bermunajat kepada Allah subhanahu wa ta'ala الفصل العاثر :في المناجاة وعرض الحاجات}

Wabai Makbluk Termulia Tiada Orang Tempat Perlindungan Beta Selain Engkau Baginda Kala Huru Hara Kiamat Melanda Semua Manusia Wahai Rasul Allah Ta ala Keagunganmu Tiada Sempit Karena Beta Tatkeala Dzat Yang Mulia Bersifat Dengan Nama Drat Penyilesa Di Antara Kemurahanmu Adalah Dunia Dan Akbirat Baqa Dan Diantara Ilmumu Adalab Ilmu Lauh Mahfudh Dan Qalam Pena Wahai Jiwa Janganlah Putus Asa Karena Dosa Besar Yang Telah Dilakukan Dalam Ampunan Allah Ta a ala Dosa Besar Seperti Kecil Dan Ringan Semoga Rahmat Allab Rabbi Ketika Dibagi Bagi Datang Dalam Pembagian Sesuai Dengan Nilai Kedurbakaan Ya Allab Jadikanlab Harapanku Tak Berbeda Dengan Apa Yang Ada Disisi-Mu Dan Jadikanlah Keyakinanku Tiada Putus - Putus Kepada-Mu Ya Allab Kasibanilah Hamba-Mu Ini Dalam Dunia Dan Akbirat Nanti Sesunggubnya Ia Punya Kesabaran Jika Bencana Menimpa Lari Tak Tahan Ya Allab Curabkan Awan Shalawat-Mu Abadi Tak Terbatas Kepada Junjungan Nabi-Mu Bagai Hujan Mengalir Deras Juga Keluarga Dan Shababatnya Kemudian Para Tabi inDan Pengikutnya Mereka Abli Taqwa Dan Kesucian Bersifat Penyantun Dan Dermawan Selagi Angin Timur Masib Mendoyongkan Dahan - Dahan Pohon Dan Selagi Pengembala Unta Senangkan Unta Dengan Merdu Suara

Syair kesepuluh di atas mengandung makna bahwa setiap hamba yang beriman tidak boleh berputus asa dari rahmat Allah subhanahu wa ta'ala. Hal itu tampak pada larik berikut; / Wahai Jiwa Janganlab Putus Asa Karena Dosa Besar Yang Telah Dilakukan/, /Dalam Ampunan Allah Ta ala Dosa Besar Seperti Kecil Dan Ringan/. Setiap orang yang beriman diwajibkan untuk terus bermunajat, meminta pertolongan, ampunan, kasih sayang Allah subhanahu wa ta'ala. serta meminta segal sesuatu hajat kepada sang Pencipta yaitu Allah subhanahu wa ta'ala. Demikian paparan kesepuluh bagian strktur sastra lisan buruda di atas. Selanjutnya, berikut ini akan dipaparkan fungsi buruda.

\section{Fungsi Sastra Lisan Buruda}

Setelah pendeskripsian isi dan makna struktur sastra lisan buruda, dapat dinyatakan bahwa sastra lisan buruda memiliki beberapa fungsi yang cukup arif dibutuhkan dalam kehidupan masyarakat Gorontalo. Berdasarkan analisis terdapat tiga fungsi yang paling utama dalam sastra lisan buruda yaitu; (1) fungsi religius; (2) fungsi ethis-teologis, dan (3) fungsi kultural. Sastra lisan buruda memiliki fungsi religius yakni; sebagai penyuluh keimanan dan ketaqwaan. Melalui syair-syair buruda terdapat pesan pengajaran kepada setiap orang yang beriman agar menyadari bahwa hanya kepada Allah subahanahu wa ta'ala semata tempat mengadu, berdoa, berharap, bertaubat, dan bermunajat memohon ampunan. Selain itu, disampaikan pula bahwa segala amal ibadah yang 
dilaksanakan oleh kaum muslimin harus bersumber pada Al Quran dan sesuai dengan sunnah nabi atau yang dicontohkan oleh Rasulullah shallallahu 'alaihi wa sallam agar mendapatkan syafaat di akhirat kelak. Dengan fungsi ini sastra lisan buruda dapat diajadikan pula sebagai sarana dakwah. Hal itu relevan dengan pernyataan Suantoko (2016,p.249) dalam penelitiannya bahwa fungsi dakwah dapat memperkaya khazanah fungsi sastra lisan itu sendiri. Seiras halnya dengan pendapat Benyamin yang dikutip Strinati (dalam Endraswara 2013,p.67) dinyatakan bahwa karya seni termasuk sastra sering ditempatkan dalam praktik keagamaan. Sehubungan dengan hal itu, dapat dinyatakan pula bahwa di balik keindahan syair-syair buruda ditemukan makna dan pesan praktik keagamaan yang berfungsi untuk menyampaikan ajaran-ajaran yang mengandung syariat yang patut dilaksanakan dan diamalkan dalam kehidupan masyarakat Gorontalo.

Selain itu, sastra lisan buruda memiliki fungsi etis. Fungsi ini secara leksikal berhubungan dengan masalah etika yang menitikberatkan pada norma dan prinsip moralitas yang dijadikan pedoman oleh setiap orang ketika bersikap dan bertindak dalam masyarakat. Fungsi etis dapat disejajarkan dengan sistem nilai yang menurut Keraf (2013,p.14-16) dipelihara sebagai sebuah kebiasaan hidup yang baik dan diwariskan melalui agama serta kebudayaan yang dianggap sebagai sumber utama baik norma maupun nilai moral. Persoalan moral meskipun bersifat absolut dan universal (Barrow, 2007,p.8), namun dapat dipahami dari pengajaran, direalisasaikan melalui sikap dan tindakan yang mengarah pada kepedulian, keadialan, dan kebaikan. Demikian halnya dalam sastra lisan buruda memiliki fungsi etis dalam kehidupan masyarakat Gorontalo. Melalui syair-syair buruda diajarkan tentang moral, etika, dan orma yang berperan sebagai pengontrol tingkah laku, hawa nafsu, dan perbuatan buruk. Masyarakat dididik tidak memperturutkan hawa nafsu, terutama terhadap pasangan muda-mudi yang sedang jatuh cinta. Hal itu penting agar kaum muda- muda tidak terjurumus pada praktik cinta yang terlarang, pergaulan bebas, dan perilaku menyimpang lainnya. Dalam konteks ini sastra lisan buruda sebagai folklore dipandang telah mengemban fungsi edukatif, yaitu membantu mendidik kaum muda sesuai pendap, p.277). Selain itu, masyarakat diingatkan dan diajarkan agar tidak bersikap dan berbuat sesuatu yang dapat menimbulkan sangsi sosial serta perbuatan dosa yang melanggar aturan Allah dan Rasul. Fungsi ini secara ringkas dikategorikan termasuk sebagai alat pengendali sosial dan pendidikan (Hutomo, 1991,p.70). Selain itu, sastra lisan buruda secara etis dapat difungsikan pula sebagai pentransfer nilai karakter. Karakter yang dimaksud yakni relevan dengan akhlak yang menurut Marzuki (dalam Wibowo, 2013,p.13) yakni merupakan nilai-nilai perilaku yang universal meliputi seluruh aktivitas manusia, baik dalam rangka berhubungan dengan Tuhan, dengan diri sendiri, dengan manusia, maupun dengan lingkungan, yang terwujud dalam pikiran, sikap, perasaaan, perkataan dan perbuatan berdasarkan norma-norma agama, hukum, tata karma, budaya, dan adat istiadat. Sastra lisan buruda memiliki fungsi etis sebagai sarana pengutaraan pesan-pesan yang mengandung pengajaran moralitas dan akhlak yang baik dengan meninggalkan perbuatan buruk berdasarkan ajaran agama islam.

Selanjutnya, sastra lisan buruda memiliki fungsi kultural yakni sebagai penguat identitas tradisi dan solidaritas masyarakat Gorontalo. Hal ini sebati dengan pendapat Dundes (1965,p.277) bahwa di antara fungsi sastra lisan sebagai bagian dari folklore adalah meningkatkan perasaan solidaritas suatu kelompok. Syair-syair Buruda sering dibawakan secara berkelompok pria maupun wanita pada hajatan pernikahan dan pembaiatan anak perempuan yang sudah masuk usia baligh (dewasa). Pada saat itu banyak keluarga besar, tentangga kompleks, dan karib sejawat, berkumpul bersama membantu persiapan hajatan dengan sambil menyimak para tokoh adat dan para orang tua melantunkan syair-syair buruda. Sayir buruda disampaikan biasanya pada malam pernikahan (sebelum akad) di rumah 
mempelai perempuan dan malam pembaiatan di rumah anak perempuan yang sudah mencapai usia baligh. Hal itu dimaksudkan dalam rangka mengedukasi dan memberikan nasehat atau petuah tentang menjaga kehormatan diri, mengendalikan hawa nafsu serta menunaikan kewajiban beribadah kepada Allah subhanhu wa ta'ala. Selain itu, sastra lisan buruda dibawakan pada malam peringatan maulid nabi Muhammad shallallahu 'alaibi wa sallam dalam rangka syiar, merefleksi, dan mengartikulasikan pesan tentang perlunya ketaatan kepada Allah subhanahu wa ta'ala serta keutaman mengikuti sunnah nabi dalam beramal ibadah. Adanya muatan ajaran agama islam seperti itu, karena diketahui syair buruda berasal dari budaya orang-orang Arab, namun telah membudaya di daerah Gorontalo. Hal itu dapat dimaklumi karena budaya itu tidak murni dan tidak dibatasi secara lokal, namun sebagai produk interkasi lintas wilayah (Barker (2003,p.41). Pendapat ini memperkuat fungsi kultural sastra lisan buruda sebagai integral budaya yang merupakan hasil interaksi antara masyarakat Arab dan Gorontalo yang telah tumbuh dan berkembang menjadi budaya Gorontalo. Secara ringkas fungsi kultural sastra lisan buruda dapat memberikan citra lokal dan representasi kebiasaaan dan perilaku kehidupan sosial budaya masyarakat Gorontalo yang sangat kental dengan nilai islami. Hal ini didukung oleh pernyataan Endraswara (2013,p.2) bahwa sastra sering dimaknai sebagai alat untuk mengajarkan perilaku budaya. Sastra lisan buruda secara kultural dapat dijadikan alat bantu yang memiliki nilai guna sebagai self and social of control dalam kehidupaan masyarakat Gorontalo. Pada kondisi demikian, diharapkan basis kesadaran masyarakat cukup kuat dengan tetap menjaga kesantunan, batasan-batasan, dan aturan yang dilandasakan pada ajaran agam islam saat berinteraksi dan bersosialisasi satu sama lain.

\section{SIMPULAN}

Sastra lisan buruda merupakan bagian dari budaya yang yang tidak hanya sekedar memiliki keindahan dalam keotonomian struktur syairnya. Di balik unsur estetis sastra lisan buruda terdapat pula pesan yang bermanfaat dalam konteks kehidupan masyarakat Gorontalo. Sastra lisan buruda memiliki pesan dan fungsi religuis, etis dan fungsi kultural yang sangat penting dipahami dan diproyeksikan dalam kehidupan masyarakat Gorontalo. Dengan demikian, sastra lisan buruda perlu dieksplorasi secara polyvocality guna merebut makna yang bermanfaat dan sebagai ikhtiar ilmiah dalam mengkaji sastra lisan buruda sebagai ekspresi budaya masyarakat Gorontalo yang perlu dilestarikan secara berkelanjutan.

\section{UCAPAN TERIMA KASIH}

Banyak pihak yang telah membantu, membimbing, serta memberikan saran dan informasi terkait dengan penelitian ini. Untuk itu disampaikan terima kasih kepada pihak LEMLIT Universitas Negeri Gorontalo dan Pimpinan Fakultas Sastra dan Budaya. Terima kasih pula dismpaikan kepada para informan dan semua pihak yang telah berartisipasi di dalam pelaksanaan peneltian ini. Tak lupa ucapan terima kasih disampaikan pula kepada Tim Reviewer jurnal pendidikan bahasa dan sastra Indonesia yang mereview artikel ini.

\section{DAFTAR RUJUKAN}

Danandjaja, J. (2002). Foklore Indonesia: Ilmu Gosip, Dongeng dan lain-lain. Jakarta: Pustaka Utama Grafiti.

Dundes, A. (1965). The Study of Foklore. Englewood, Cliffs, N.Y: Prentice-Hall.

Barker, C. (2003). Cultural Studies: Theory and Practice (2 $2^{\text {nd }}$ edition). London: SAGE Publications.

Barrow, R. (2007). An Introduction to Moral Philosophy and Moral Education. USA, Canada: Routledge.

Endraswara, S. (2008). Metodologi Penelitian Sastra. Yogyakarta: Media Pressindo.

$$
\text { (2013). Metodologi Penelitian }
$$

Antropologi Sastra. Yogyakarta: Ombak.

Firmanda, G. E., Effendy, C., \& Priyadi, A. T. (2018). Struktur dan fungsi sastra 
lisan masyarakat senganan kecamatan sekadau hilir kabupaten sekadau.Jurnal Pendidikan dan Pembelajaran Khatulistiwa, 7(3).

Hestiyana. (2017). Fungsi Sastra Lisan Banjar Tatangar. Jurnal Gramatika, Vol. 5(2)

Hutomo, S.S. (1991). Mutiara Yang Terlupakan. Jawa Timur: HISKI Surabaya

Ikram, A. (1980). Perlu Memelibara Sastra Lama. Jakarta: Analisis Kebudayaan (AK) Tahun 1, Nomor $3 \mathrm{hlm}$ 73-74.

Keraf, S. (2013). Etika Lingkungan Hidup. Jakarta: Buku Kompas.

Mahsun. (2005). Metode Penelitian Bahasa. Jakarta: PT Raja Grafindo Persada.

Ratna, I.N.K. (2007). Sastra dan Cultural Studies. Yogyakarta: Pustaka Pelajar.
Robson, A.D. (1988). Pengkajian Sastra-Sastra Tradisional Indonesia. Jakarta: P3B

Suantoko, S. (2016). Fungsi Sastra Lisan "Tanduk" Masyarakat Genaharjo Kabupaten Tuban Bagi Masyarakat Pendukungnya. Jurnal Pendidikan Bahasa dan Sastra, 16(2), 246-256.

Tuloli, N. (2003). Puisi Lisan Gorontalo. Depdiknas Pusat Bahasa.

Vansina, J. (1985). Oral Tradition as History. London, England: The University of Wisconsin Press.

Wibowo, A. (2013). Pendidikan Karakter Berbasis Sastra. Yogyakarta: Pustaka Pelajar. 